\title{
A Process Oriented Design Pedagogy: KFUPM Sophomore Studio
}

\author{
Dr Ashraf M Salama, Associate Professor of Architecture
}

College of Environmental Design, King Fahd University of Petroleum and Minerals (KFUPM) KFUPM Campus, P.O. Box 848, Dhahran 31261, Saudi Arabia

Email: asalama@kfupm.edu.sa or asalama@gmail.com

\begin{abstract}
The design studio is the heart of architectural education where most schools of architecture devote $30 \%$ to $50 \%$ of their curriculum to design training and teaching. The design studio is the kiln where future architects are moulded and the main forum for creative exploration, interaction, and assimilation. However, theorists, academics, and researchers voiced the opinion that most design studio teaching continues to provide students with little understanding of the value of design as a technique, a process, or a set of purposive procedures. This paper argues for a process oriented design pedagogy by outlining an assessment of traditional teaching practices and by introducing a model that advocates the view that the process and the product are equally valuable components of studio teaching. Constituted in two major categories of process and teaching style, the model addresses students' individual differences. The implementation of the model at KFUPM sophomore studio is reported together with examples of outcomes of students' work.
\end{abstract}

Keywords: Design Studio, Collaborative Design/Learning, Cognition, Problem Based Learning 


\section{Acknowledgement}

The author acknowledges the support of KFUPM and extends his thanks to sophomore architecture students at the College of Environmental Design and to Dr. Richard Lukens who participated in the implementation of the proposed model.

\section{Introduction: a Process Based Architectural Design Pedagogy}

In his book: The Sciences of the Artificial, Herbert Simon (1976) argues that the act of design is a form of problem solving. He sees designing, in its purist form, as an optimisation process thereby ignoring controversial, uncertain, and unique situations. To the contrary, design literature (Lawson B, 1992; Schon D, 1988) points out that the act of design, in its generic sense, consists of making representations of things to be materialised since designers put things together to create new artifacts. Thus, the design process is intended to function based on intuition, logical treatment, and rigorous reasoning. Schon (1988) argues, and rightly so, that a design process is a reflective conversation between the materials of a given design situation. In this respect, one could argue that it is a process that involves phases of analytical understanding, critical thinking, and creative decision making. However, design does not occur in a linear manner; it involves integrated thinking where continuous interaction between the phases takes place.

Recent literature suggests that architectural design pedagogy stands accused of focusing more on form issues, while oversimplifying programmatic and contextual contexts within which buildings are created (Anthony K, 1991; Cuff D, 1991; Koch A et al, 2002; Salama A, 1995, 1998, 2002; Sanoff H, 2003; Schon D, 1981, 1983, 1985, 1988; Seidel A, 1994; Stamp A, 1994). Concomitantly, traditional teaching practices suggest that typical architectural design pedagogy adopts a product based approach, where emphasis is often placed upon exploring solutions and the development of form manipulation skills, while students' design actions continue to be tacit and internalized (Salama A, 1999).

In response to the product based approach, educators have adopted the systematic process of design promoted by the design methodology movement of the late 1960s introducing the analysis-synthesis paradigm; an approach that proved to fall short of dealing with design as an integrated process. The main criticism is that the results of the analysis phase are usually ponderous statements of the blindingly obvious and that the overall design situation is handled within a fragmented sequence. Students are often unable to translate the results of the first analytic phase into a successful design and are led to believe that an optimal solution will signify the end of the process. In this approach, it is assumed that a creative leap will translate the program into the design and students keep searching for that leap and thus are unable to complete their design and meet project submission deadlines.

There are two basic project types in the teaching of architectural design. The first is hypothetical where design aspects are not real but simulated. The second is real life where a real problem and client exist as integral components of the delivery of a solution. Both share two major features; what to design and how to design. What to design is about 
beginnings and ends, while how to design is about means. What to design is bound by the project program in its most general and most specific qualities (Mann D, 1992). It is characterised by proposing human activities that are appropriate for certain types of spaces or forms (Salama A, 1995). In essence, what to design must respond to the institutions of society, to society's cultural directives, and to the overall lexicons of building. How to design is centred on methods, a term that implies that design is a set of actions and procedures a design student performs on purpose. Design in this respect can be studied, tested, and most importantly, it can be taught. To design is to undertake a series of activities that lead to desired end results.

The position being taken by the author is that both what to design and how to design are essential aspects of studio teaching. However, one should note that no process of design is inherently superior to another. One process might be appropriate for one set of conditions while another might work better for different conditions. Most importantly, some processes are more able to be taught than others, since they are based on systematic procedures, while at the same time meet students' abilities. Therefore, this paper calls for a fresh look at the way in which students' abilities are developed in a manner that is more responsive to the design issues they encounter in the studio. The paper reports on a sophomore studio taught by the author at the College of Environmental Design, King Fahd University of Petroleum and Minerals (KFUPM). It outlines a criticism of traditional teaching practices with an emphasis on the design process and the route taken in the studio. Based on this criticism, the paper introduces a model devised by the author to view the process and product as equally integral components of studio teaching. The model addresses design as process and teaching and learning styles adopted in the studio. It simplifies the process of design into a set of procedures for educational purposes; responding to students' abilities. The implementation of the model is presented based on an international elementary school design project assignment, together with examples of outcomes of students' work.

\section{Assessment of Traditional Studio Teaching: a Brief Literature Account}

In order to assess the status of traditional studio teaching pedagogy, two strategies have been employed. The first is a content analysis of the available theoretical literature and the second is a literature review of the results of the surveys that have been conducted on pedagogical aspects of design. This assessment process has identified a number of issues stated in the literature that are integral to contemporary studio teaching. Such issues are classified into two categories; negative tendencies and positive attitudes as outlined in Tables 1 and 2, each of which is broken down into two components that represent the overall studio teaching approach. These are the design process in the studio and the teaching style adopted by the studio director. This classification is based on the fact that the processes and procedures applied in the studio are governed by the way in which studio assignments are delivered in terms of content and key issues. On the other hand, instructors tend to approach each design assignment with a collection of ideas and techniques that, when coordinated, become a teaching style that is influenced by the route taken in the studio. 
TABLE 1: Negative tendencies resulting from the assessment of design pedagogy

\begin{tabular}{|c|c|c|}
\hline Category & Author & Negative Tendencies \\
\hline \multirow{8}{*}{$\begin{array}{l}\text { Design } \\
\text { Process } \\
\text { in the } \\
\text { Studio }\end{array}$} & Kay J 1975 & $\begin{array}{l}\text { - The process of problem definition is crucial and needs to } \\
\text { be addressed in the studio }\end{array}$ \\
\hline & $\begin{array}{l}\text { Watson D } \\
1993\end{array}$ & $\begin{array}{l}\text { - Design experience is limited to concept formation and } \\
\text { schematic design }\end{array}$ \\
\hline & $\begin{array}{l}\text { Watson D } \\
1993\end{array}$ & $\begin{array}{l}\text { - Students have insufficient opportunity to attain the ability } \\
\text { to explore the nature of design }\end{array}$ \\
\hline & $\begin{array}{l}\text { Weber C } \\
1994\end{array}$ & $\begin{array}{l}\text { Design studios place an emphasis on the finished } \\
\text { presentation of a sketch design rather than the route taken } \\
\text { in the studio }\end{array}$ \\
\hline & $\begin{array}{l}\text { Salama A } \\
1995\end{array}$ & $\begin{array}{l}\text { Design instructors focus on the how of design although } \\
\text { what and why of design are unavoidable components in } \\
\text { the design process of a real life project }\end{array}$ \\
\hline & $\begin{array}{l}\text { Salama A } \\
1995\end{array}$ & $\begin{array}{l}\text { - Although many architectural educators believe that } \\
\text { research should be introduced in the design studio, a } \\
\text { large number of them do not have a clear definition of } \\
\text { research, and how to introduce it in the studio }\end{array}$ \\
\hline & AIAS 2003 & $\begin{array}{l}\text { - Students work side by side, but alone, often guarding their } \\
\text { ideas from each other, competing for the attention of the } \\
\text { studio critic }\end{array}$ \\
\hline & AIAS 2003 & $\begin{array}{l}\text { The synthetic processes of design in which negotiation } \\
\text { and collaboration are most critical and difficult, are limited } \\
\text { to individual efforts }\end{array}$ \\
\hline
\end{tabular}




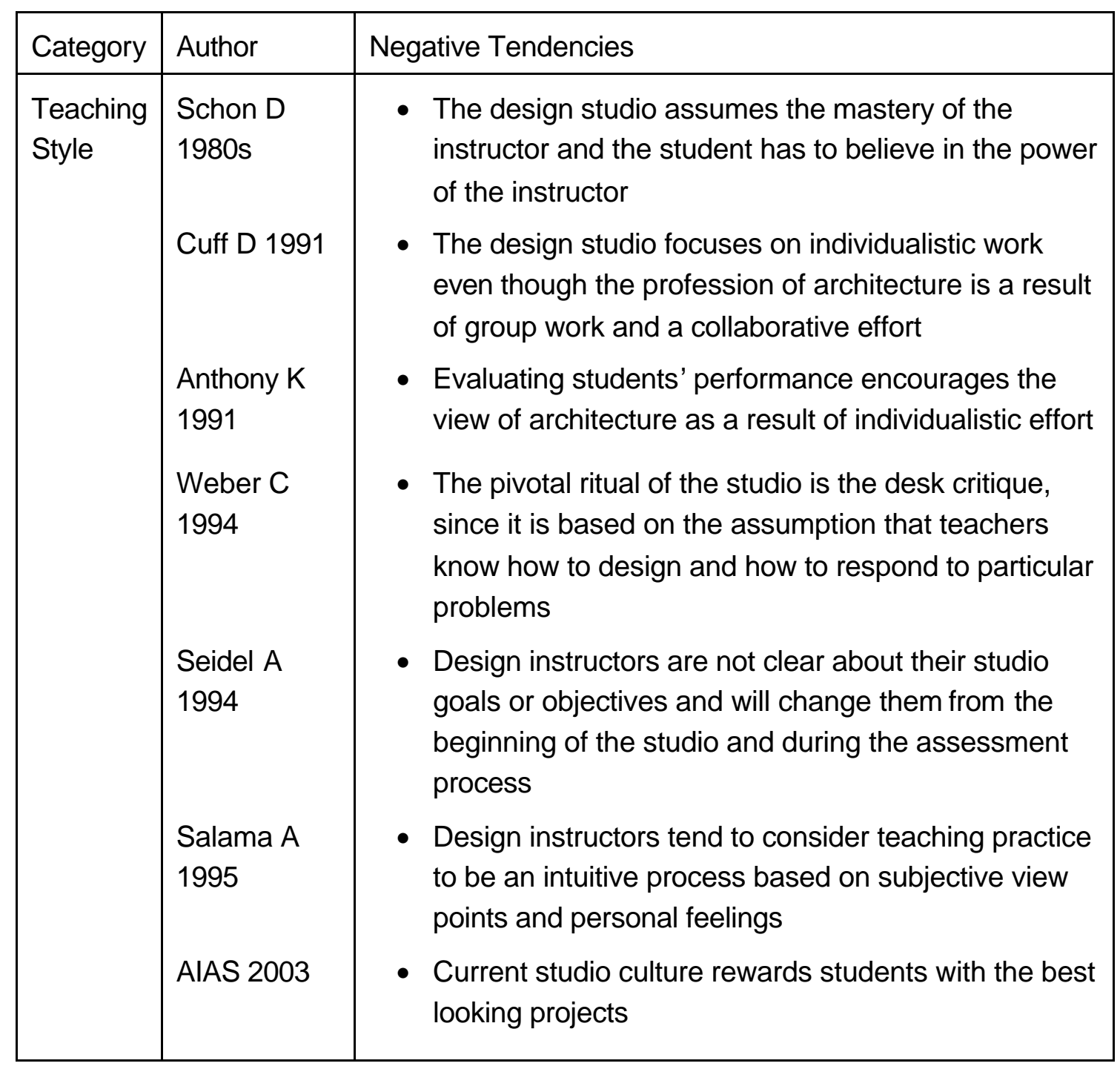


TABLE 2: Positive attitudes resulting from the assessment of design pedagogy

\begin{tabular}{|c|c|c|}
\hline Category & Author & Positive Attitudes \\
\hline \multirow{7}{*}{$\begin{array}{l}\text { Design } \\
\text { Process } \\
\text { in the } \\
\text { Studio }\end{array}$} & Simmons G 1978 & $\begin{array}{l}\text { The process emphasises acquiring knowledge while } \\
\text { producing design alternatives }\end{array}$ \\
\hline & Sanoff H 1979 & $\begin{array}{l}\text { - The process encourages group discussion for } \\
\text { identifying design intentions }\end{array}$ \\
\hline & Sanoff H 1979 & $\begin{array}{l}\text { - The process focuses on transforming behavioural } \\
\text { information into architectural form }\end{array}$ \\
\hline & Robinson J 1983 & $\begin{array}{l}\text { - The process is to explore design rather than to simply } \\
\text { reach a solution }\end{array}$ \\
\hline & Robinson J 1983 & $\begin{array}{l}\text { - The process represents the programming phase as a } \\
\text { crucial part in the studio }\end{array}$ \\
\hline & $\begin{array}{l}\text { Goldschmidt G } \\
1983\end{array}$ & $\begin{array}{l}\text { The process includes information gathering and } \\
\text { defining imperatives as primary steps }\end{array}$ \\
\hline & AIAS 2003 & $\begin{array}{l}\text { The ability to serve design as a process serves a } \\
\text { graduate for a lifetime }\end{array}$ \\
\hline \multirow{9}{*}{$\begin{array}{l}\text { Teaching } \\
\text { Style }\end{array}$} & Simmons G 1978 & - The style is based on self and peer evaluation \\
\hline & Sanoff H 1979 & - The style focuses on individual and group activities \\
\hline & Sanoff H 1979 & $\begin{array}{l}\text { - The style permits learning about the process of change } \\
\text { in a dynamic environment }\end{array}$ \\
\hline & $\begin{array}{l}\text { Goldschmidt G } \\
1983\end{array}$ & $\begin{array}{l}\text { - The style is based on instruction and reaction modes of } \\
\text { thinking }\end{array}$ \\
\hline & Ledewitz S 1985 & $\begin{array}{l}\text { The style is based on teaching students how to } \\
\text { differentiate relevant from irrelevant information }\end{array}$ \\
\hline & Davis H 1983 & - Students' individual differences are a major concern \\
\hline & Wendler W 1995 & $\begin{array}{l}\text { Integrating knowledge generating ideas into design } \\
\text { should be part of the everyday practices in the studio } \\
\text { environment }\end{array}$ \\
\hline & Penny T 2003 & $\begin{array}{l}\text { - If we want professionals to be confident contributing } \\
\text { leaders in society, we should take every care in making } \\
\text { sure that the educational system encourages } \\
\text { confidence (not defensiveness), empathy (not self } \\
\text { centredness) and team work (not a star mentality) }\end{array}$ \\
\hline & Habraken J 2003 & $\begin{array}{l}\text { We need to integrate knowledge about the everyday } \\
\text { environment in design teaching }\end{array}$ \\
\hline
\end{tabular}


While the assessment corroborates very alarming negative tendencies and shortcomings, a number of positive attitudes are observed. By and large, the results reveal a growing interest and awareness of the importance of addressing the process as an integral component of studio teaching pedagogy.

\section{A Proposed Process Oriented Model of Studio Pedagogy}

In response to the critical analysis of studio pedagogy, a model was developed by the author in an attempt to integrate the process into studio teaching. The model aims to improve students' understanding of information relevant to specific design problems while being engaged in generating alternative design solutions. It is devised based on three assumptions that can be outlined as follows:

- $\quad$ Students have a limited set of sources for their ideas due to unfamiliarity with techniques for exploring design issues.

- $\quad$ Students have difficulty in exploring issues that go beyond the basic formal principles.

- $\quad$ Students rarely accomplish the incorporation of a variety of design issues in their solutions.

\section{The process}

The model adopts a comprehensive multilayered process that encompasses two major components. The first component is analytical understanding and includes exploration and information gathering, while the second is creative decision making that includes the interpretation and development of design schematics. Figure 1 illustrates a conceptual diagrammatic analysis of the studio model.

The first stage is exploration which includes the delivery of the assignment where project objectives are clarified. In this stage, students are sensitised toward understanding key design issues related to the project and the building type. An initial program is also offered to provide an impetus generating conceptual ideas about what the project may include. The process of sensitising students may take a number of forms that include a lecture presentation outlining design issues, presenting important similar examples, and discussing emerging issues from the latest literature as it relates to the project. Following the lecture, one or more studio sessions are devoted to exploring critical design aspects and the specific issues that need to be encountered in the project. This occurs by conducting group discussions that involve the development of reactionary mechanisms. This allows students to react to generalisations and specifics related to programmatic, functional, contextual, and image issues. 


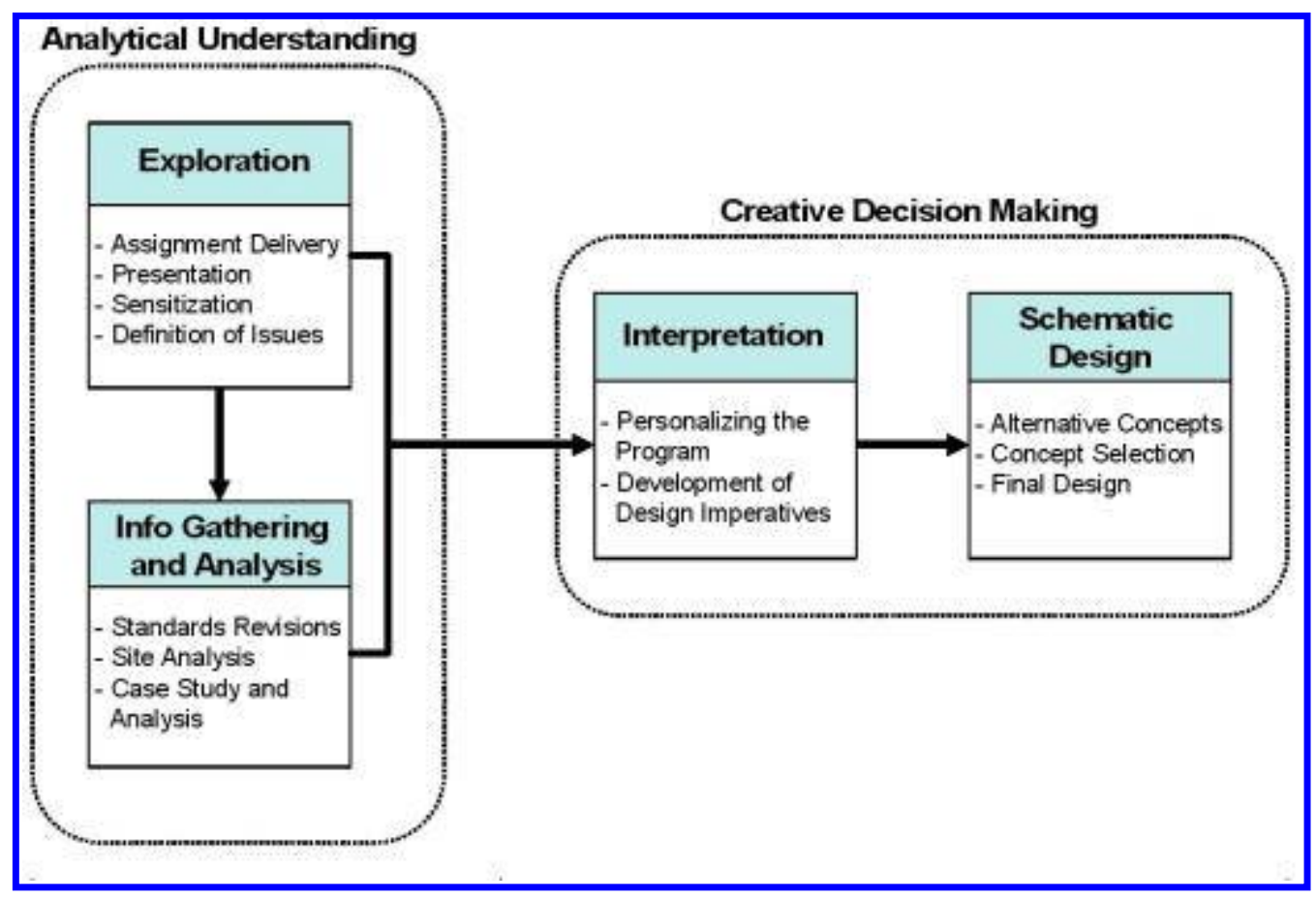

Figure 1: Stages of the proposed process based studio teaching model

The second stage is information gathering involving three procedures; the first is a review of standards, the second is a case study where an analysis of a similar project takes place, and the third is site analysis. The revision of standards involves critical analysis of basic functional issues and adjacency requirements. The case study involves a comprehensive understanding of a project example by relating key design issues introduced in the first stage and the standard information to the example under investigation. While analysing the selected case, students are required to focus on functional, climatic, contextual, and image aspects as major design determinants. They are also asked to develop a critique by listing advantages and disadvantages of the cases selected. The degree of sophistication of site analysis varies according to the nature of the project, the site, and the total project duration. However, site walkthroughs to discover realities and to identify constraints and opportunities are a basic requirement.

The third stage is interpretation where the information and data gathered are transformed into knowledge bases. Based on their understanding of the key design issues, site constraints, standards, and the results of the case study, students are required to develop a personalised program and a set of design imperatives. At this stage, students interpret the information and decide on priorities. Imperatives are developed according to personal interpretation, which turns the body of information into manageable issues. The act of interpretation is a selective process that employs rules and imperatives by relating issues one to another so as to develop a framework for design.

The fourth stage is developing a schematic design. It involves generation of at least two alternative concepts based on the personalised program and the imperatives established in the third stage. Each student debates the two alternatives concepts in terms of their appropriateness and on that basis one of them is selected for further development into two 
and three dimensional scale designs. The quality of the resulting architectural design is based on the fulfilment of a number of conditions that include:

- $\quad$ Reflecting the key design issues and the information processed in the final design scheme.

- $\quad$ Showing how the imperatives are dealt with toward developing a final design.

\section{The teaching style}

The model is conceived on the basis of individual differences and the fact that students are not all alike, since learning capacities vary as much as their personalities. While the studio is structured into phases, the teaching style adopts the multiple intelligence theory (Lazear $\mathrm{D}$, 1991 \& 1992) that corroborates that there are several different methods of learning, including logical, visual, and verbal. Therefore, throughout the process, students are engaged in a variety of activities that relate to these methods.

The division of the studio process into four stages is based on adopting the split brain theory (Williams L, 1983) that recognizes that people possess two different but complementary ways of processing information; a linear step by step style that analyses the parts that make up a pattern (the left-side of the brain), and a spatial-relational style that seeks the construction of patterns (the right side of the brain). Concomitantly, the left side is usually described as analytical, linear, and sequential and that it produces knowledge by inferential logic. The right side is described as synthetic and holistic and that it produces knowledge through intuition and imagination.

A closer look at the studio process confirms the full utilization of students' capacities as illustrated in Figure 2. In the first component that encompasses analytical understanding, students are engaged in rationally deductive procedures including exploration and information gathering. In the second component of the process that accommodates creative decision making, students are engaged in intuitive inductive activities that include interpretation and alternative generation. Consequently, throughout the studio process, the modes of thinking are analytic, synthetic and evaluative as the students are involved in these modes intellectually and socially in the form of group and individual work.

The studio process involves conditions whereby students are encouraged to take on the primary responsibility to critique one another and to learn what it means to critique objectively. Group work is a priority at least in the first two stages of the process where students learn to discuss critical issues, analyse cases, and define issues they deem important, and to make analytic decisions with others who disagree with their values. These processes require verbal and graphic presentations that help students explore and expose differences of opinions and positions.

Students get feedback from the instructor in two modes; group reviews and pin-ups while minimizing desk critiques. This allows for exploring confusing issues and much can be learned from comparing a student's own interpretation with that of his/her colleagues. Throughout the process, a distinction is made between two teaching modes: instruction and 
reaction. Instruction occurs through facilitating the processes of exploration, acquiring and analysing information, personalising the program, and developing design imperatives.

Reaction occurs by relating students' outcomes throughout the process to the requirements and instructions introduced by the studio instructor and by relating the knowledge outcome resulted from the earlier stages to the students' design alternatives.

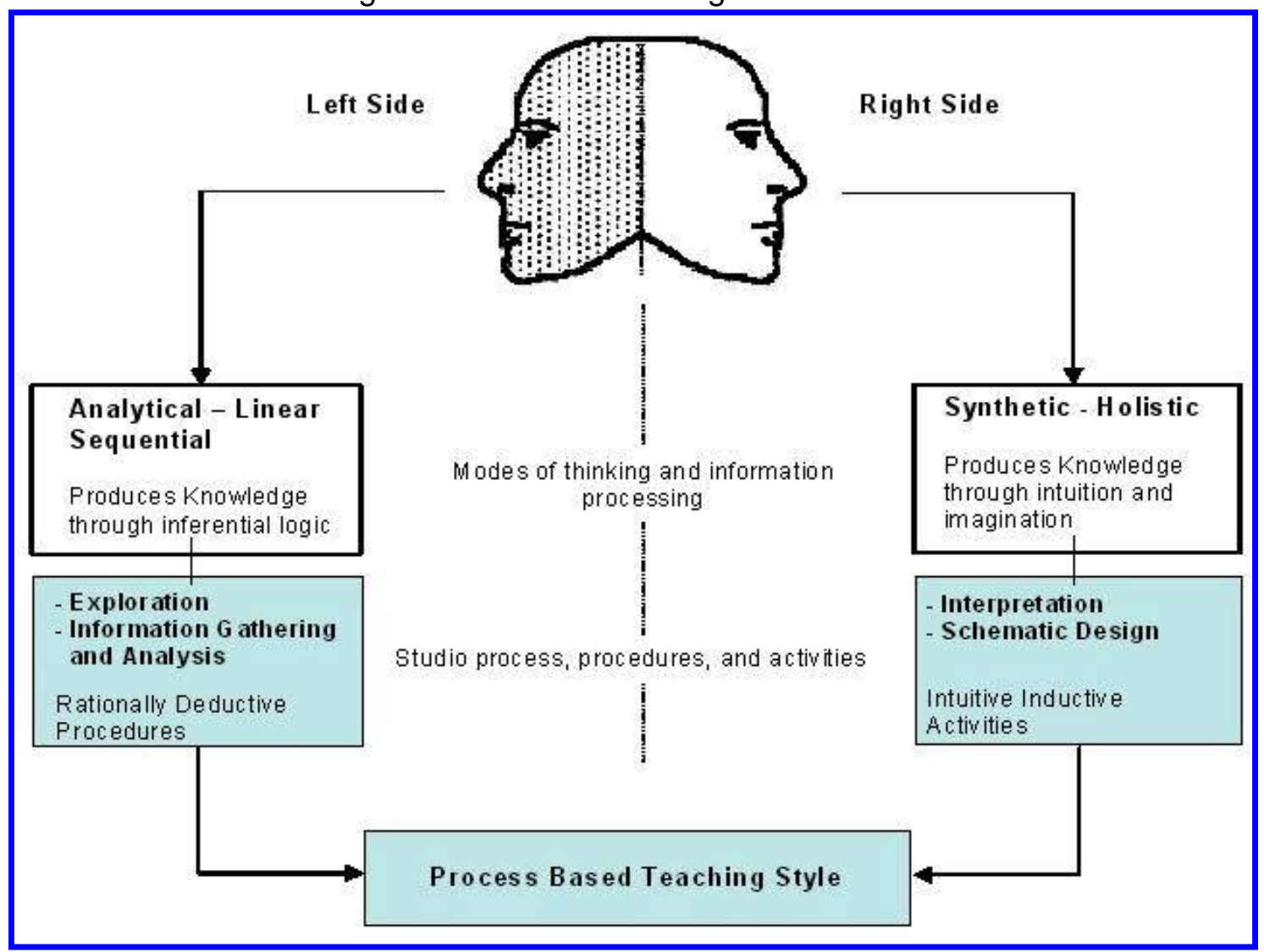

Figure 2: The teaching style adopted throughout the studio process

\section{Implementation of the Model: KFUPM Sophomore Studio}

Students come to sophomore studios at KFUPM after passing successfully two drawing, basic design, and modelling studios. Thus, one would expect that they have no or little experience in design. However, in their freshman year, students are introduced to general design issues mainly in history and theory courses. The model has been implemented in a studio assignment in 2004 with a group of 14 students enrolled in the second sophomore studio. Students have been already exposed to design projects in the first sophomore studio and have acquired basic knowledge about the process of design.

The assigned project was designing an international elementary school. All studio activities took place in a step by step integrated manner leading to final design solutions. The site of the project is located on the coastal strip of the city of Al Khobar in the eastern province of Saudi Arabia. The total duration for the assignment was seven weeks.

An interactive lecture presentation was delivered to draw students' attention to some of the important issues that pertain to elementary schools and schooling. Group discussions were 
conducted to debate relevant aspects of school design resulting in the definition of a number of key design issues. The first issue explored was to create a school within a school by articulating the academic house concept, where the school building is divided into clusters to increase the children's sense of belonging. The school building as a heart of the community was the second issue discussed with students; a concept that emphasises that the support facilities of the school should be accessible to the neighbourhood in which it is located to create a dynamic environment after school hours and during vacations. The relationship between students' achievement and the physical aspects of the classroom was the third important concept; features include efficient use of colours, natural lighting, noise control, and dividing the classroom into learning corners.

Students were divided into groups and played three design games to abstract the essential characteristics of the context and the programmatic requirements. One game focused on exploring different spatial typologies of classrooms and the way in which they may achieve desired learning objectives; the second was to examine the school building image, while the third placed emphasis on developing building blocks to explore adjacency alternatives. These gaming exercises helped students to conceptualise the most critical issues that need to be emphasised.

The information gathering stage involved preliminary revision of data books and space requirements, preliminary site analysis and case study and analysis. Group walkthroughs were conducted in the site to identify potentials of orientation and vehicular and pedestrian movement and contextual constraints. In this phase, students were able to critique the case based on the design issues explored in the first stage while comparing the standards with the project case under investigation. These steps were performed on an individual basis. However, pin-up presentations took place at regular intervals where students were given the opportunity to evaluate the resulting analyses of their colleagues.

The interpretation phase was relatively short where in a week students were to develop personalised programs based on the knowledge acquired in the first two stages and to establish a list of design imperatives. This was based on prioritising design issues. In this phase, students were required to identify space requirements and adjacencies. Design imperatives were to satisfy site constraints and key design issues.

Translating the personalised programs and design imperatives into a physical form, each student developed two preliminary alternatives and was required to evaluate them in terms of advantages and disadvantages. Pin-ups and peer evaluations were a major part of this stage. Each student selected an alternative for further development. Most students were able to address key design concepts and programmatic requirements and to reflect design imperatives they have established in their final design solutions.

\section{Studio project outcomes}

Two projects are selected to elucidate how critical design issues were translated into students' final designs as illustrated in Figures 3 and 4 . The first project emphasises how social and community aspects are integrated into school design. The spatial layout is 
designed to create a "heart" for the school with direct access to the community. The design breaks up the academic houses into cluster units of three classrooms. Support functions act as connectors between the units and each includes art room, teachers' office and lounge space, and team interaction area. The objective of this spatial organization is to offer opportunities of continuous interaction between teachers and children. Classrooms are designed utilising the typical rectangular shape with a clear definition of learning areas within each classroom. Orientation of classrooms to the north is a key design aspect to reduce the consumption of energy by minimizing AC use. Indirect daylighting is introduced to create a pleasing environment while reducing glare and brightness.

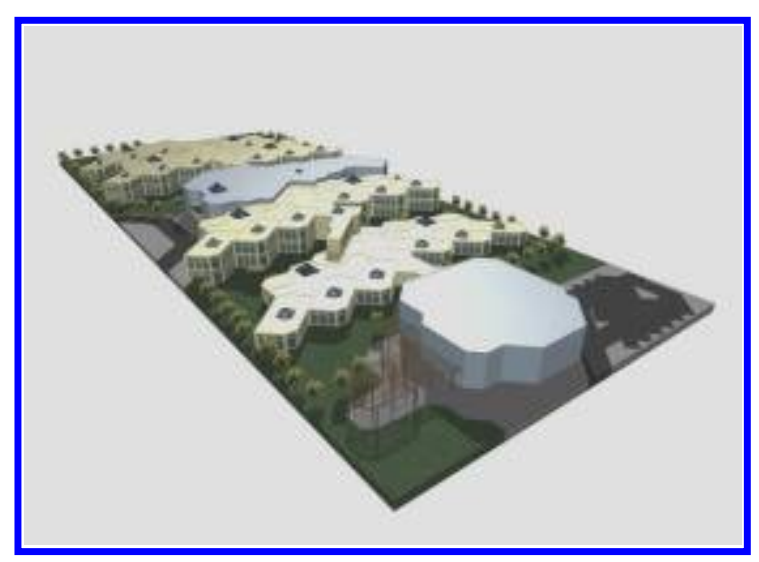

Overall School View

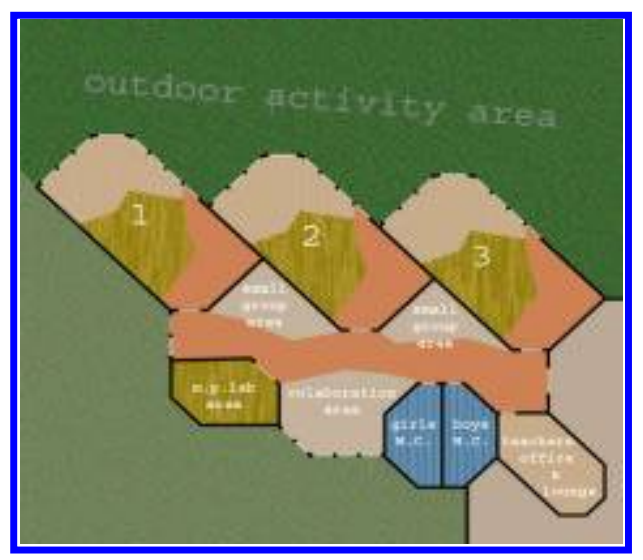

Cluster Organization

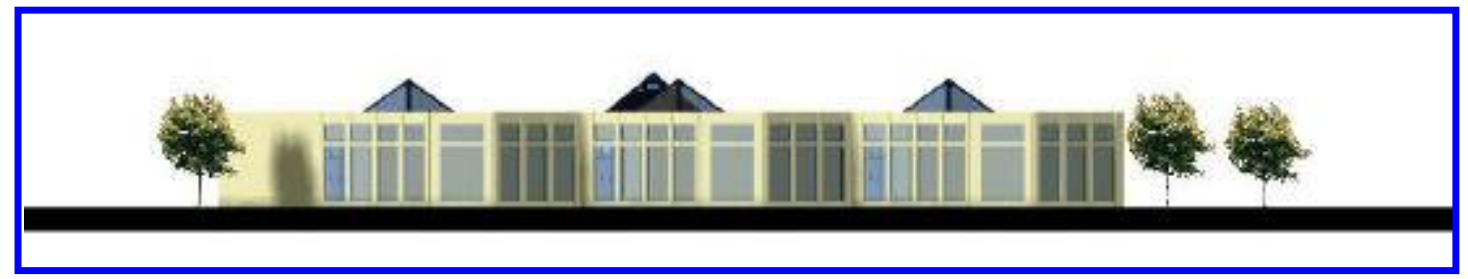

Façade of a Cluster

Figure 3: First project of student Yasser Nassif

The second project places emphasis on developing a visual identity for the school by creating a series of skylights that take a contemporary form of the "Barajeel', a dominant element in local Saudi architecture traditionally used for climatic treatment. The design adopts a mall-like layout with a spine dividing the educational section and other support functions. It includes three academic houses with classrooms taking the L-shape typology. This is to allow for cooperative group learning and team teaching. Each classroom has its own outdoor area while the academic house has a larger outdoor area that accommodates various group functions. Corridors are designed in a manner that integrates small group activities into the circulation by extended learning areas outside of the classrooms to develop a dynamic visual environment.

The preceding outline of students' projects corroborates that the process oriented design pedagogy and the teaching style adopted have dramatically influenced the quality of students' work. Key design issues together with design imperatives have been transformed 
into final alternatives that reveal a deeper insight into the understanding of what it means to prioritise issues and personalise programs. While the design experience students went through placed high value on the process, their verbal description, visual analysis, and final design delineate how a good process would lead to a successful outcome.

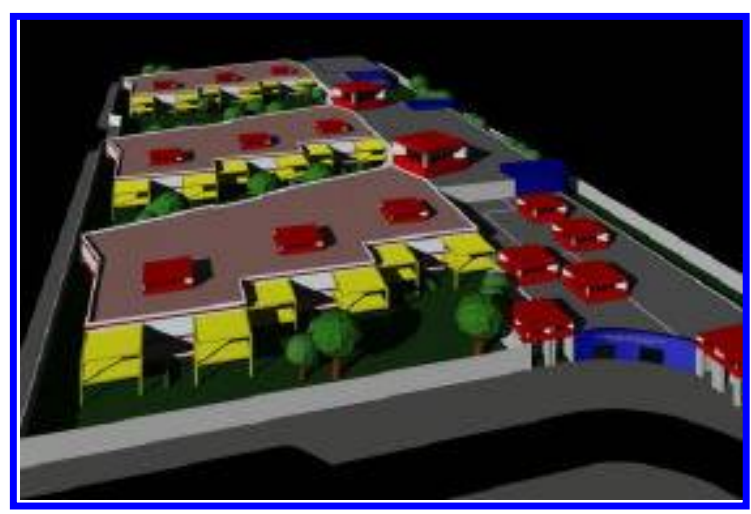

Overall School View

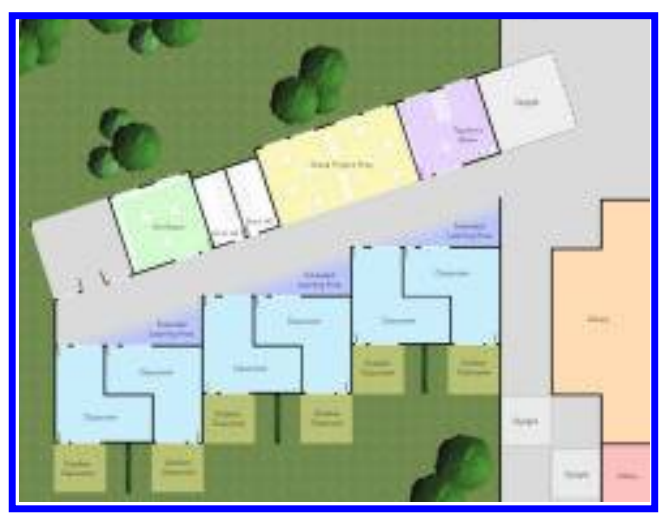

Cluster Organization

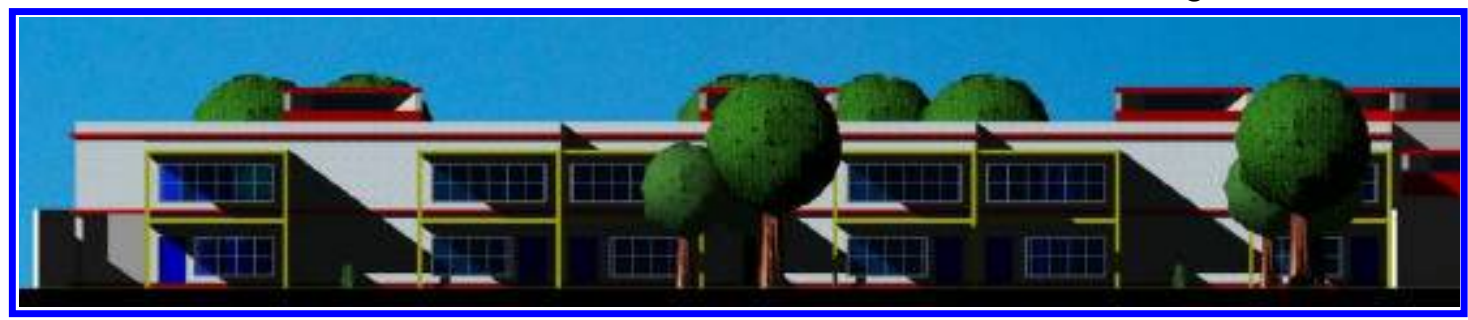

Façade of a Cluster

Figure 4: Second project of student Waleed Ghamdi

\section{Conclusion}

The intention of this paper was to propose a new process oriented studio teaching model. The paper has presented an overview assessment of traditional studio teaching practices based on content analysis and literature review. The results of the assessment delineate that while form manipulation skills appear to be superior to process aspects, a growing awareness of the value of the process in studio pedagogy is clearly on the rise. Based on adopting and adapting the multiple intelligence and the split brain theories, the model is structured in terms of process and teaching style while the process is constituted in four main stages: exploration, information gathering and analysis, interpretation, and schematic design. These stages address specific aspects that meet students' individual differences and thinking capabilities.

Implementing the model with KFUPM sophomore students reveals that the process and the teaching style have enhanced students' understanding of the relationship between what to design and how to design and of the interaction between design beginnings, means, and ends. It is believed that a process oriented design pedagogy would help students to have more control over their design actions and decisions, would invigorate their critical analysis and creative decision making skills, while at the same time foster their capacity to shift 
between different modes of design thinking. It is also believed that structuring the teaching in the studio in a series of activities and events that require specific tasks would lead to design experiences that successfully integrate systematic design thinking while at the same time not compromising the formal qualities of the students' final designs.

\section{References}

AIAS: The American Institute of Architecture Students (2003). The Redesign of Studio Culture. http://www.aiasnatl.org

Anthony, Kathryn (1991) Design Juries on Trial: The Renaissance of the Studio. New York, NY: Van Nostrand Reinhold.

Cuff, Dana (1991) Architecture: The Story of Practice. Cambridge, MA: MIT Press.

Davis, Howard (1983). A Pattern Language in a Teaching Studio. Journal of Architectural Education. Vol. 36 (3).

Goldschmidt, Gabriela (1983) Doing Design - Making Architecture. Journal of Architectural Education. Vol. 37 (1).

Habraken, John (2003) Questions that will not Go Away: Some Remarks on Long Term Trends in Architecture and their Impact on Architectural Education. Keynote Speech: Proceedings of the Annual Conference of the European Association of Architectural Education-EAAE. Hania, Crete, Greece. P. 32-42

Kay, John (1975) Architectural Education Needs a New Blueprint. Change. June, 16-21

Koch, Aaron et al. (2002) The Redesign of Studio Culture, Studio Culture Task Force, Washington, DC: The American Institute of Architecture Students-AIAS.

Lawson, Brian (1992) How Designers Think. London, UK. Butterworth.

Lazear, David (1991) Seven Ways of Teaching: The Artistry of Teaching with Multiple Intelligences. Palatine, IL: IRI Skylight Publishing Inc.

Lazear, David (1992) Teaching for Multiple Intelligences. Bloomington, IN: Phi Delta Kappan Educational Foundation.

-Ledewitz, Stephanie (1985) Models of Design in Studio Teaching. Journal of Architectural Education. Vol. 38 (2).

-Mann, Dennis, A. (1992) Teaching Designing. Design Studies. Vol. 13 (4), 411-429

Penny, Thompson (2003) Discussion with the President of the AIA. The American Institute of Architects: http://www.aia.org

Robinson, Julia (1983) Programming as Design. Journal of Architectural Education. Vol. 37 (2). 
Salama, Ashraf (1995) New Trends in Architectural Education: Designing the Design Studio. Raleigh, NC: Tailored Text and Unlimited Potential Publishing.

Salama, Ashraf (1998) A New Paradigm in Architectural Pedagogy. In J. Teklenburg et al. (eds) Shifting Balances: Changing Roles in Policy, Research, and Design. Eindhoven, Netherlands: EIRSS Publishers. P. 128-139.

Salama, Ashraf (1999) Incorporating Knowledge about Cultural Diversity into Architectural Pedagogy. In W. O'Reilly (ed) Architectural Knowledge and Cultural Diversity. Lausanne, Switzerland: Comportments. P. 135-144.

Salama, Ashraf (2002) Environmental Knowledge and Paradigm Shifts: Sustainability and Architectural Pedagogy in Africa and the Middle East. In A. Salama et al. (eds) Architectural Education Today: Cross Cultural Perspectives. Lausanne, Switzerland: Comportments. P. 51-63

Sanoff, Henry (1979) Design Games. Los Altos, CA: William Kaufmann.

Sanoff, Henry (2003) Three Decades of Design and Community. Raleigh, NC: College of Design, North Carolina State University.

Schon, Donald, A. (1981) Learning a Language, Learning to Design. Architectural Education Study. Cambridge, MA: Consortium of East Coast Schools of Architecture.

Schon, Donald, A. (1983) The Reflective Practitioner: How Professionals Think in Action. New York, NY: Basic Books.

Schon, Donald, A. (1985) The Design Studio: An Exploration of Its Tradition and Potentials. London, England: RIBA Publications.

-Schon, Donald, A. (1988) Toward a Marriage of Artistry and Applied Science in the Architectural Design Studio. Journal of Architectural Education. Vol. 41 (4), 16-24.

Seidel, Andrew (1994) Knowledge Needs the Request of Architects. In Seidel, A. Banking on Design: Proceedings of the $25^{\text {th }}$ Annual International Conference of the Environmental Design Research Association-EDRA, St. Antonio, TX. P. 18-24.

Simmons, Gordon (1978) Analogy in Design: Studio Teaching Models. Journal of Architectural Education. Vol. 31 (3).

Simon, Herbert (1976) The Sciences of the Artificial. Cambridge, MA: MIT Press.

-Stamp, Arthur, E. (1994) Jungian Epistemological Balance: A Framework for Conceptualizing Architectural Education. Journal of Architectural Education. Vol. 48 (2), 105-112.

Watson, Donald (1993) Towards a New Paradigm in Education. Proceedings of the Conference on Knowledge Based Architectural Education: Reconfiguring the Studio. Architectural Research Centres Consortium. St. Antonio, TX. P.13-14.

Weber, Chris (1994). The Integrated Design Studio. Design Studies. Vol. 15 (1). 
Dr Ashraf M Salama: A Process Oriented Design Pedagogy: KFUPM Sophomore Studio

Wendler, Walter (1995) Building a Culture of Scholarship in a College of Architecture. Proceedings of the Conference on Knowledge Based Architectural Education: Reconfiguring the Studio. Architectural Research Centres Consortium, Milwaukee, WI.

Williams, Linda (1983) Teaching for the Two Sided Mind. New York, NY: Simon and Schuster. 
This article has been cited by:

1. Hui Cai, Sabir Khan. 2010. The Common First Year Studio in a Hot-desking Age: An Explorative Study on the Studio Environment and Learning. Journal for Education in the Built Environment 5:2, 39-64. [Abstract] [Full-text] [PDF] [PDF Plus] 